\title{
Avaliação comparativa de ferramentas web de apoio à tradução através de critérios de usabilidade e ergonomia cognitiva
}

\author{
Rossana da Cunha Silva e Lincoln P. Fernandes*
}

\section{Introdução}

A área das ferramentas de apoio à tradução $\left(C A T\right.$ tools $\left.{ }^{l}\right)$ seguiu a tendência dos avanços tecnológicos correntes após o surgimento da web 2.0, seja com a atualização de sistemas já existentes ou com a disponibilização de novas ferramentas no setor. Esta evolução também teve destaque na área de usabilidade e ergonomia, onde novas tecnologias e ferramentas surgiram para facilitar o desenvolvimento de aplicações e, assim, prover uma melhor experiência de uso aos seus usuários. No entanto, apesar de ser uma preocupação compartilhada por muitos, a aplicação de critérios de ergonomia cognitiva e usabilidade se limita a um pequeno número de pesquisas. Além disso, verifica-se uma menor prioridade a fatores relacionados à facilidade de uso das ferramentas de apoio à tradução pelos seus usuários.

Neste contexto, este artigo busca apresentar sob a perspectiva da usabilidade e ergonomia cognitiva, o que poderia ser melhorado em ferramentas de apoio à tradução com o objetivo de proporcionar uma visão mais próxima à experiência vivida pelos usuários deste tipo de programa. Além de apresentar formas de avaliar como se dá a interação de usuários com sistemas da área de tradução, a aplicação de uma metodologia prática e de

\footnotetext{
* Rossana da Cunha Silva é mestra em Estudos da Tradução e licenciada em Letras-Inglês pela Universidade Federal de Santa Catarina (UFSC). É também bacharel em Ciência da Computação pela Universidade Federal do Pará (UFPA). Lincoln P. Fernandes é Professor de Estudos da Tradução e Secretário de Relações Internacionais da Universidade Federal de Santa Catarina (UFSC).

${ }^{1}$ Computer-aided translation tools (ferramentas de apoio à tradução).
} 
SILVA e FERNANDES, Avaliação comparativa de ferramentas web de apoio à tradução através de critérios de usabilidade e ergonomia cognitiva

baixo custo como a que se descreve aqui pode contribuir para as pesquisas sobre as ferramentas CAT.

Neste artigo são abordados os resultados obtidos a partir da análise realizada em duas ferramentas CAT, chamadas Google Translator Toolkit (GOOGLE, 2016) e Wordfast Anywhere (WORDFAST, 2016). A avaliação comparativa foi realizada em duas etapas: (i) exploratória e (ii) por meio de uma lista de verificação de usabilidade. Os objetivos desta análise são: (i) identificar a aplicação de métodos conhecidos de usabilidade e ergonomia cognitiva em ferramentas CAT; (ii) comparar duas ferramentas CAT disponíveis on-line; e (iii) aplicar métodos de avaliação de usabilidade e ergonomia nos sistemas em questão. Sob o ponto de vista de Nielsen (1993, p. 102), os benefícios de aplicar alguns dos métodos de usabilidade e ergonomia para avaliar a interface de um sistema visam verificar quão bem as pessoas podem usar uma determinada interface. Nielsen (1993, p. 101) também faz recomendações sobre como corrigir os problemas identificados.

Cybis et al. (2010, p. 246) corroboram a combinação de técnicas de avaliação de ergonomia e usabilidade, e acrescentam que as mesmas são diagnósticas e tomam como base as verificações e inspeções de aspectos ergonômicos que possam estar divergentes da maneira como o usuário realiza sua tarefa, ou mesmo das características dos usuários que utilizam tal ferramenta. De acordo com Massey e Ehrensberger-Dow (2011), esta preocupação ergonômica é fortemente relacionada à forma como tradutores interagem com várias ferramentas e como a sua habilidade técnica é construída.

Nesta primeira seção, buscou-se apresentar o estudo proposto, bem como a análise sugerida. Na seção 2 , será mostrado um resumo de alguns dos aspectos gerais relativos à literatura utilizada durante a pesquisa. $\mathrm{Na}$ seção 3, aborda-se a metodologia de forma a elencar os materiais e instrumentos utilizados. Na seção 4 , a análise e discussão de dados têm o propósito de justificar o presente estudo. Na quinta e última seção, dispõem-se as conclusões, encaminhamento e referências. 
SILVA e FERNANDES, Avaliação comparativa de ferramentas web de apoio à tradução através de critérios de usabilidade e ergonomia cognitiva

\section{Fundamentação teórica}

As tecnologias de tradução tornaram-se imprescindíveis na profissão do tradutor, de tal forma que é difícil imaginar um tradutor iniciar uma tarefa sem o uso de algum tipo de ferramenta computacional, como um dicionário on-line ou um editor de textos (BOWKER, 2015, p. 88). Conforme Alcina (2008, p. 80), a "relação entre a tradução e a tecnologia teve seu início com o desenvolvimento de dicionários eletrônicos e bases de dados terminológicas, além do início da internet e sua utilização em pesquisa, ensino e prática da tradução", tendo como exemplos o surgimento de ferramentas CAT e o desenvolvimento de sistemas de tradução automática. Sob ponto de vista semelhante, Kenny (2011, p. 302) destaca que a utilização de computadores se tornou infraestrutura fundamental na área da tradução, devido à profissão ser altamente ligada à tecnologia.

\subsection{Tradução assistida por computador}

A tradução assistida por computador (CAT), segundo Garcia (2015, p. 68), refere-se ao uso do computador com o intuito de facilitar o trabalho do tradutor durante o processo de tradução. Os sistemas de tradução assistida por computador diminuem o custo de projetos de tradução, aumentando, assim, qualidade e produtividade. Ainda segundo o autor, apesar das ferramentas surgirem em 1970, foi só a partir do início de 1990 que o uso dos sistemas CAT teve seu maior crescimento, principalmente devido à necessidade das empresas tornarem seus produtos e serviços disponíveis para outras línguas e mercados (localização ${ }^{2}$ ). $\mathrm{O}$ autor ainda menciona que, devido aos prazos limitados e grandes volumes de textos, surgiu também a necessidade de que o mesmo texto fonte fosse utilizado simultaneamente por diferentes equipes de tradutores. Além disso, a criação do corretor e revisor de tradução como novos elementos deste tipo de ferramenta faz com que o tradutor compartilhe com o programa a tarefa de revisão do produto final, seja completamente ou através da tarefa de pós-edição.

\footnotetext{
2 Conforme Declercq (apud MALMKJÆR \& WINDLE, 2011, p. 262), a localização diz respeito a tornar um produto linguística e culturalmente apropriado à localidade de destino onde o mesmo será utilizado ou comercializado.
} 
SILVA e FERNANDES, Avaliação comparativa de ferramentas web de apoio à tradução através de critérios de usabilidade e ergonomia cognitiva

É importante ressaltar que as ferramentas CAT englobam aplicações que foram desenvolvidas e projetadas com o enfoque da tradução. Segundo Garcia (2015, p. 68), apesar de editores de texto, corretores gramaticais, ortográficos e outros recursos eletrônicos auxiliarem no trabalho do tradutor, estes não podem ser considerados ferramentas CAT, visto que sua criação se destina a um público maior. Os sistemas CAT permitem a reutilização de traduções, com o uso de computadores, para o armazenamento de informações, bem como para a pesquisa e recuperação do que é armazenado. Para isso, são utilizadas as chamadas memórias de tradução (Translation Memory - TM), que consistem em bases de dados contendo segmentos de textos alinhados com suas traduções em múltiplas línguas (CHAN, 2015, p. 68-70; GAMBIER \& DOORSLAER, 2010, p. 60-61; QUAH, 2006, p. 94; KENNY, 2011). Como exemplo de sistemas CAT conhecidos, podemos citar: WordFast, WordSmith Tools, SDL Trados, Transit NXT, OmegaT, Across Language Server, memoQ, MateCat, Google Translator Toolkit, entre outros.

Com a evolução dos sistemas CAT, suas funcionalidades principais foram complementadas por outras, tais como ferramentas para alinhamento, ferramentas de extração para compilação de glossários bilíngues, gestão terminológica, filtros de conversão e gerenciamento de projetos de tradução. Atualmente, o sistema CAT mais conhecido e amplamente comercializado em uso, conforme Bowker e Fisher (2010, p. 60), é o ambiente de tradução (Translation Environment Tool - TEnT), também conhecido como Workbench ou Workstation, que contém um conjunto de ferramentas funcionando, muitas vezes, com a integração de memórias de tradução e de um sistema de gestão terminológica.

\subsection{Usabilidade e ergonomia cognitiva}

Segundo Carroll (2009), a interação humano-computador (IHC) é uma área de pesquisa e prática que surgiu no início de 1980 como parte da ciência da computação, e que tinha como objetivo principal englobar a ciência cognitiva e a engenharia de fatores humanos. Além disso, a IHC se preocupa com a concepção, avaliação e implementação de sistemas de computação que sejam interativos para o uso humano, além dos principais fenômenos que a cercam (HEWETT et al., 1992). A IHC abrange a parte visual, os sis- 
SILVA e FERNANDES, Avaliação comparativa de ferramentas web de apoio à tradução através de critérios de usabilidade e ergonomia cognitiva

temas de informação, o processo de desenvolvimento de sistemas, além de várias áreas de design.

Dentro da IHC, destaca-se uma área chave denominada "usabilidade" que, de acordo com a norma ISO 9241-11 (2002, p. 3), é a capacidade de um produto ser empregado por usuários específicos para alcançar objetivos específicos com eficácia, eficiência e satisfação em um contexto específico de uso. Conforme Nielsen (1993, p. 24-25), a:

\begin{abstract}
Utilidade está relacionada em saber se o sistema pode ser utilizado para alcançar determinado objetivo. Ela pode ser dividida em duas categorias: utilidade e usabilidade (GRUDIN, 1992); onde a utilidade se concentra em determinar se a funcionalidade do sistema é capaz de realizar o que necessita, enquanto que a usabilidade se preocupa em quão bem os usuários podem usar essa funcionalidade.
\end{abstract}

A pesquisa em usabilidade é recente e uma de suas abordagens se caracteriza pelas relações entre ergonomia, psicologia cognitiva e ciência cognitiva. A palavra ergonomia é de origem grega: ergon (trabalho) e nomos (leis) e vem a designar a ciência do trabalho. Conforme o IEA - The International Ergonomics Association (2000):

\footnotetext{
Ergonomia (ou fatores humanos) é uma área de conhecimento que se preocupa em compreender as interações entre seres humanos e outros elementos de um sistema. A profissão aplica teoria, princípios, dados e métodos para realizar projetos que otimizem o bem-estar humano e o desempenho geral do sistema.
}

A ergonomia possui três domínios de especialização: (i) física, preocupa-se com as características anatômicas, antropométricas, fisiológicas e biomecânicas do ser humano, e como estas se relacionam com a atividade física; (ii) cognitiva, preocupa-se com os processos mentais, como por exemplo: percepção, memória, raciocínio e resposta motora, uma vez que estes afetam as interações entre o homem e os elementos de um sistema; e (iii) organizacional, refere-se à otimização de sistemas de abordagem sociotécnica, incluindo suas estruturas organizacionais, políticas e processos (IEA, 2000). 
SILVA e FERNANDES, Avaliação comparativa de ferramentas web de apoio à tradução através de critérios de usabilidade e ergonomia cognitiva

Pode-se dizer que a usabilidade é medida, enquanto que a ergonomia da interface deve ser avaliada com base em recomendações e critérios ergonômicos (CYBIS et al., 2010, p. 16-17). Tais critérios constituem um suporte para avaliação rápida dos problemas mais comuns que um sistema possa apresentar, visto que os sistemas computacionais e suas interfaces com o usuário nada mais são do que ferramentas cognitivas capazes de facilitar a percepção, raciocínio, memorização e a tomada de decisão (CYBIS et al., 2010, p. 204; BASTIEN \& SCAPIN, 1993, p. 3).

\section{Procedimentos metodológicos e etapas do estudo}

Os métodos utilizados neste trabalho seguem a sugestão de Cockton (2013) em empregar uma combinação de técnicas durante uma inspeção de usabilidade, visto que esse tipo de investigação tem a característica de se adaptar a projetos específicos ou contextos organizacionais. Existem diversas pesquisas que seguem a mesma orientação, como as pesquisas sobre os mais diversos tópicos de usabilidade, relacionadas ao grupo: Nielsen Norman Group (NIELSEN, 2002); além das associadas ao projeto europeu MAUSE Towards the MAturation of Information Technology USability Evaluation (LAW et al., 2005), que teve como objetivo o desenvolvimento, avaliação e comparação de métodos de avaliação de usabilidade.

$\mathrm{O}$ estudo proposto tem como ponto de partida duas ferramentas CAT. São elas: Wordfast Anywhere (2016) e Google Translator Toolkit (2016). A investigação inicia através do teste de comparação, que tem como ponto principal confrontar produtos concorrentes para melhor compreender as vantagens e desvantagens de modelos de interfaces. (RUBIN; CHISNELL, 2008, p. 37). O teste de comparação foi dividido em duas etapas, sendo a primeira delas um teste exploratório, considerando a experiência da avaliadora e seu conhecimento prévio na área. A segunda etapa se deu com a avaliação de uma funcionalidade específica que está presente nas duas ferramentas analisadas: ambiente de tradução - Workbench. Nesta segunda etapa, foi aplicada uma lista de verificação formulada com base no proposto por Flórez (2012, p. 154-156) sobre como avaliar a usabilidade de um sistema. 
SILVA e FERNANDES, Avaliação comparativa de ferramentas web de apoio à tradução através de critérios de usabilidade e ergonomia cognitiva

Com vista a validar a aplicação de critérios ergonômicos e de usabilidade, formularam-se, para este estudo, as seguintes hipóteses:

- Hipótese 1: Com base nas ferramentas CAT selecionadas, acreditase que a dificuldade de usar sistemas deste tipo se deve à pouca preocupação com o usuário, levando à construção de sistemas diferentes entre si e que não proporcionam uma interação de fácil uso.

- Hipótese 2: Com a confirmação da hipótese 1, acredita-se que não haja aplicação de métodos de usabilidade e ergonomia antes da disponibilização de ferramentas CAT aos seus usuários.

\subsection{Google Translator Toolkit}

A primeira ferramenta CAT selecionada, denominada Google Translator Toolkit (2016), é um editor on-line que, segundo a empresa responsável Google Inc. (2016), "permite que o usuário aperfeiçoe e compartilhe suas traduções". Ainda segundo a empresa, o programa foi desenhado para tradutores profissionais, mas está disponível para qualquer pessoa utilizar. A ferramenta permite: (i) traduzir e localizar vários tipos de conteúdo; (ii) usar memórias de tradução e glossários; (iii) editar arquivos; (iv) compartilhar e colaborar com outras pessoas; (v) armazenar; (vi) exportar em múltiplos formatos. Uma de suas vantagens, segundo informações da própria ferramenta, é que por ser um editor on-line é possível modificar e compartilhar traduções que foram geradas com a tradução automática do Google Translate (GOOGLE, 2016). A seguir, é possível visualizar o ambiente de tradução do programa na Figura 1. 
SILVA e FERNANDES, Avaliação comparativa de ferramentas web de apoio à tradução através de critérios de usabilidade e ergonomia cognitiva

Figura 1 - Google Translator Toolkit Workbench

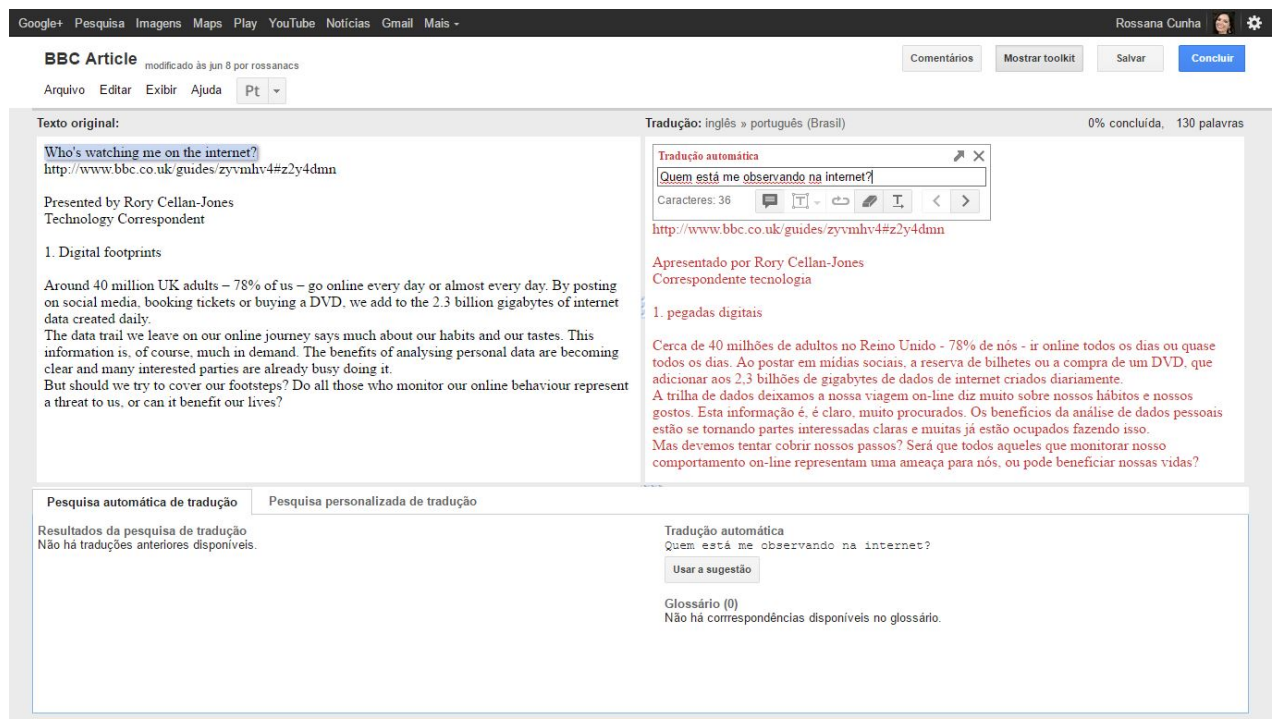

Fonte: Google Inc. (2016).

\subsection{Wordfast Anywhere}

O segundo programa selecionado, denominado Wordfast Anywhere (2016), caracteriza-se por ser a versão web da ferramenta CAT Wordfast Pro. Segundo a empresa, é possível utilizar a ferramenta de qualquer navegador, qualquer sistema operacional, através de dispositivos como smartphone ou iPad, ou seja, "anywhere" ${ }^{3}$ (WORDFAST, 2016). Além de possibilitar aos tradutores a facilidade de se trabalhar em qualquer lugar, não há necessidade de instalação de atualizações, visto que a ferramenta web sempre estará em sua última versão. A empresa também assegura a privacidade e confidencialidade das informações, bem como, oferece diversas opções gratuitamente. $\mathrm{O}$ ambiente de tradução da ferramenta é apresentado na Figura 2.

3 De qualquer lugar. 
SILVA e FERNANDES, Avaliação comparativa de ferramentas web de apoio à tradução através de critérios de usabilidade e ergonomia cognitiva

Figura 2 - Wordfast Anywhere (2016).

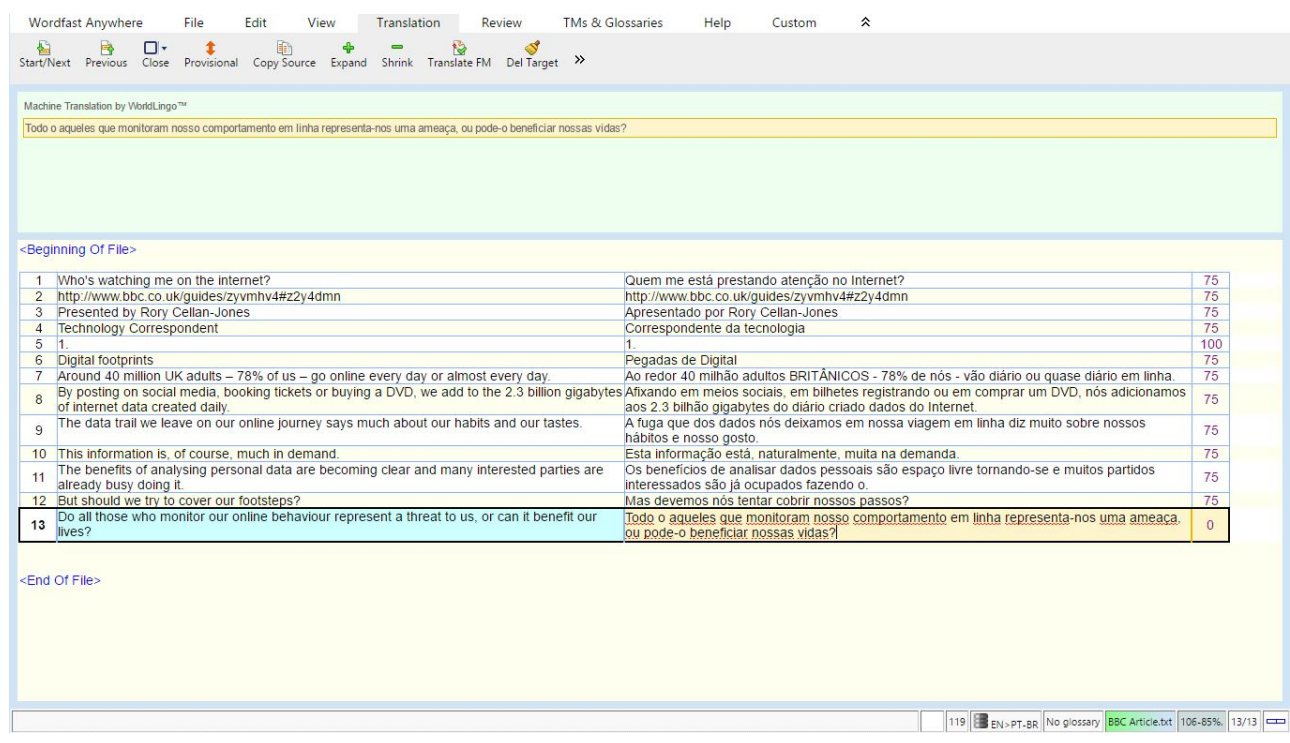

Fonte: Wordfast Anywhere (2016).

\title{
3.3. Instrumento de análise: avaliação comparativa
}

A avaliação comparativa é um método para determinar como um site se apresenta em relação aos seus concorrentes. Esse tipo de teste pode ser conduzido de forma mais holística, onde são avaliados critérios mais gerais de usabilidade e ergonomia cognitiva; ou com maior enfoque, para se comparar características específicas, elementos ou conteúdo (SCHADE, 2013). Segundo Schade (2013):

\begin{abstract}
As avaliações podem ser realizadas por especialistas, em que um expert em usabilidade analisa os projetos com base em sua experiência e conhecimento de usabilidade, ou por testes competitivos de usabilidade, onde os usuários completam um conjunto de tarefas usando [dois] ou mais sites concorrentes (p. 2).
\end{abstract}

Como o teste de comparação pode ser utilizado em conjunto com outros testes, selecionou-se em meio às diversas ferramentas CAT, duas que possuem versões gratuitas e acessíveis através da internet. O objetivo é contrastar diferentes estilos de interface para comparar produtos concor- 
SILVA e FERNANDES, Avaliação comparativa de ferramentas web de apoio à tradução através de critérios de usabilidade e ergonomia cognitiva

rentes e, assim, compreender melhor as vantagens e desvantagens de modelos de interfaces existentes na área (RUBIN; CHISNELL, 2008).

\subsection{Procedimento metodológico}

A avaliação comparativa foi realizada pela própria autora, devido a sua expertise em usabilidade, proveniente de sua experiência profissional como analista de sistemas há quase 15 anos. $\mathrm{O}$ teste de comparação realizado em duas etapas teve início com o teste exploratório, considerando critérios de usabilidade e ergonomia. A segunda etapa se deu com a avaliação do próprio workbench que está presente nos dois sistemas avaliados. Nesta última etapa, aplicou-se a lista de verificação formulada por Flórez (2012, p. 154156) para avaliação de usabilidade. Flórez ainda sugere a escala: de 1 a 3 , em que (1) corresponde a inaceitável, (2) aceitável e (3) satisfatória.

A lista de verificação foi adaptada ao contexto do presente artigo, conforme apresentado no Apêndice A, onde podemos identificar três categorias principais: (i) interface do usuário; (ii) facilidade de uso; (iii) documentação. Devido à sua fácil aplicação, as duas ferramentas foram avaliadas por essa lista logo após a avaliação exploratória. Conforme afirmam Rubin e Chisnell (2008), quando se comparam projetos, não há um projeto "vencedor". A melhor interface será uma combinação das alternativas, com os melhores aspectos dispostos a formar uma interface híbrida. Acredita-se, também, que a avaliação comparativa proposta venha a fornecer uma base para a discussão sobre os métodos de usabilidade aplicados a ferramentas CAT. Temos, como métrica a ser utilizada após a aplicação da lista de verificação de usabilidade, os critérios definidos conforme a Tabela 1:

Tabela 1 - Métricas de Usabilidade na Avaliação Comparativa.

\begin{tabular}{|l|l|}
\hline \multicolumn{2}{|c|}{ Usabilidade } \\
\hline Subcaracterística & Critérios de aceitação (Pontuação mínima) \\
\hline Interface do usuário & Igual ou maior que oito $(>=8)$. \\
\hline Documentação & Igual ou maior que seis $(>=6)$ \\
\hline Facilidade de uso & Igual ou maior que oito $(>=8)$. \\
\hline
\end{tabular}

Fonte: Adaptado de Flórez (2012, p. 159). 
SILVA e FERNANDES, Avaliação comparativa de ferramentas web de apoio à tradução através de critérios de usabilidade e ergonomia cognitiva

Na Tabela 1, aplica-se a métrica sugerida por Flórez (2012, p. 159) após totalização dos itens verificados no sistema. Caso o sistema apresente uma pontuação mínima de oito para a "interface do usuário" e para a "facilidade de uso", assim como uma pontuação mínima de seis para "documentação", poderemos afirmar que o sistema possui usabilidade aceitável.

\section{Análise e discussão de dados}

Neste artigo, sugerimos alguns dos possíveis fatores relacionados à falta de usabilidade e ergonomia em sistemas de tradução, especificamente em ferramentas CAT. A avaliação comparativa foi realizada de duas formas, sendo a primeira exploratória, seguindo a orientação das hipóteses formuladas no item 3; e a segunda, com a aplicação de uma lista de verificação de usabilidade com pontos mais gerais do sistema.

\subsection{Primeira etapa: avaliação exploratória}

A análise foi realizada no sistema operacional Windows 8.1 e no navegador Chrome, ambos com as atualizações mais recentes. Buscou-se validar o uso principal da ferramenta CAT, que é o de tradução de um documento, a fim de identificar os problemas mais comuns de usabilidade e ergonomia, bem como oferecer sugestões para melhoria dos sistemas analisados.

\subsubsection{Google Translator Toolkit}

A análise realizada teve início no editor on-line, onde são apresentados os seguintes itens: "traduções", "solicitações", "marcadores", "compartilhar com...", e "ferramentas". O programa já demonstra uma divergência em relação ao uso, devido à escolha da palavra "enviar", o que sugere enviar email, pois se assemelha à ferramenta Gmail (utilizada para envio de emails). A escolha de um termo mais relacionado ao processo tradutório seria a mais adequada, como, por exemplo: "nova tradução", "novo arquivo" etc. Após clicar no botão "enviar", foi aberta nova janela para "fazer upload de documento para tradução", com diversas opções sobre idiomas e tipos de conteúdo. A tela para carregamento de arquivo para tradução revela-se com um nível alto de informações, o que pode causar desconforto ou confusão ao usuário de tradução, visto que o mesmo já acessa um vasto 
SILVA e FERNANDES, Avaliação comparativa de ferramentas web de apoio à tradução através de critérios de usabilidade e ergonomia cognitiva

número de ferramentas (dicionários, páginas de pesquisa, arquivo do texto fonte etc.).

Depois de concluído o carregamento do arquivo, o usuário é direcionado para uma nova página onde há dois campos principais: "texto original", em preto, e "tradução", em vermelho. No campo "tradução" é apresentada a tradução automática do texto original, e ao editar parte desta tradução, é aberta uma pop-up na própria janela principal com o trecho a ser alterado. Além do problema com as cores (visto que o vermelho não seria visualizado por um daltônico, por exemplo; ou o desconforto gerado pelo contraste preto e amarelo da janela de atalhos do teclado, sobreposta à tela principal de cor branca - vide Figura 3), a ferramenta utiliza páginas distintas, o que impede que o usuário consiga saber onde está no sistema naquele momento, além de não conseguir retornar ao menu principal. Outro problema identificado está relacionado ao excesso de informações dispostas na página, bem como à falta de ajuda nos campos apresentados em tela.

Figura 3 - Avaliação comparativa - exploratória - Google Translator Toolkit.

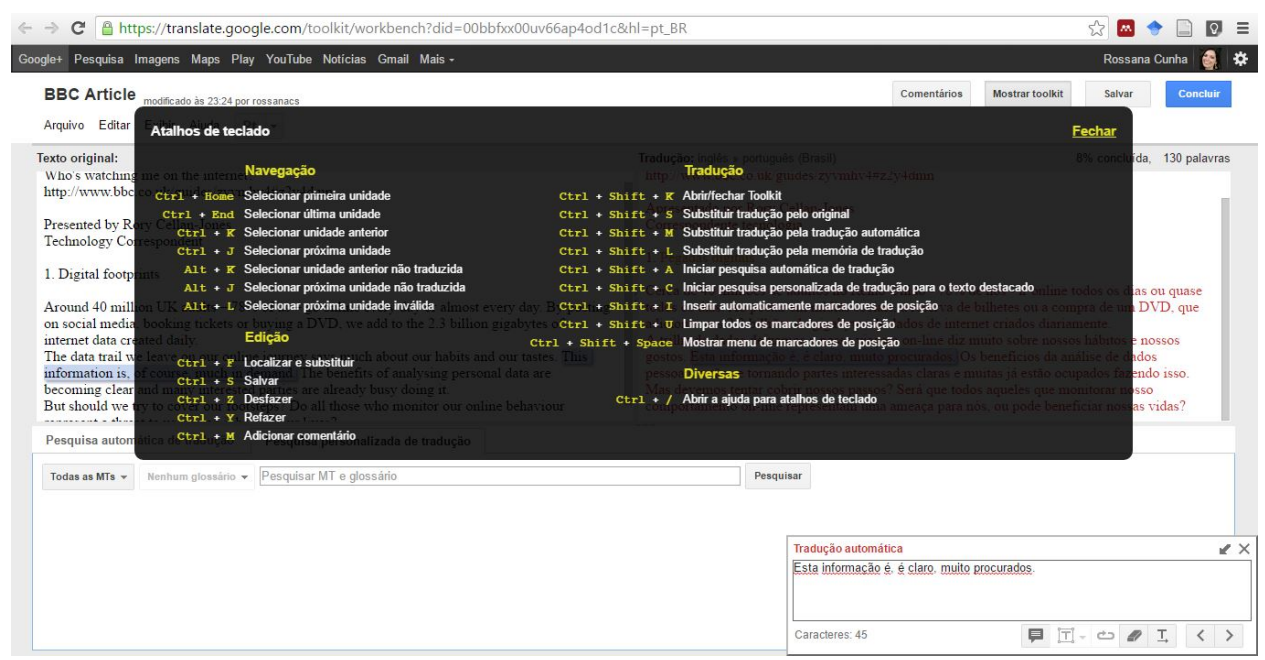

Fonte: Google Translator Toolkit (2016).

\subsubsection{Wordfast Anywhere}

A análise começou com o carregamento de um arquivo no menu "File" após clicar no botão "Upload", onde é exibida uma pop-up com opções para 
SILVA e FERNANDES, Avaliação comparativa de ferramentas web de apoio à tradução através de critérios de usabilidade e ergonomia cognitiva

a seleção do arquivo desejado. O texto original é apresentado no workbench da ferramenta, habilitando a aba "Translation". É possível configurar teclas de atalho para facilitar o uso da ferramenta e utilizar a tradução automática existente no próprio programa. A ferramenta apresenta funcionalidades semelhantes à sua versão desktop e consistência com o uso de termos, além de padrões nos itens existentes no programa. Apesar de a familiaridade com a interface desktop ser um aspecto positivo na ferramenta, pois mantém a conformidade entre as duas versões, pode-se constatar que a utilização deste estilo de interface não atende aos usuários de sistemas web, visto suas características, como utilização, através de um navegador que requer páginas facilmente carregáveis, opções de autopreenchimento em campos de seleção, além de uma apresentação que siga os padrões atuais recomendados pela organização responsável $\mathrm{W} \mathrm{C}^{4}$.

A última atualização da página aparece como sendo em 09/08/2016 na sua versão 4.10.7, portanto as características da página estão desatualizadas segundo as novas tecnologias. Por outro lado, atendem a algumas das necessidades referentes à usabilidade e ergonomia cognitiva. Por exemplo: ajuda nas páginas, tanto para o usuário mais experiente quanto para o iniciante; a concisão de termos apresentados; a exibição de erros para que o usuário tenha como corrigir e tentar a ação novamente. A ferramenta não atende a alguns itens relacionados ao controle do usuário (NIELSEN \& MOLICH, 1990), que vão desde saídas rápidas após escolhas erradas, até a habilidade de desfazer ou refazer ações, o que preserva os usuários de seguirem passos preestabelecidos; segundo a ErgoList (2011), a condução "diz respeito igualmente às informações que permitem ao usuário identificar o estado ou contexto no qual ele se encontra, bem como às ferramentas de ajuda e seu modo de acesso".

${ }^{4}$ https://www.w3.org/ 
SILVA e FERNANDES, Avaliação comparativa de ferramentas web de apoio à tradução através de critérios de usabilidade e ergonomia cognitiva

Figura 4 - Avaliação comparativa - exploratória - Wordfast Anywhere.

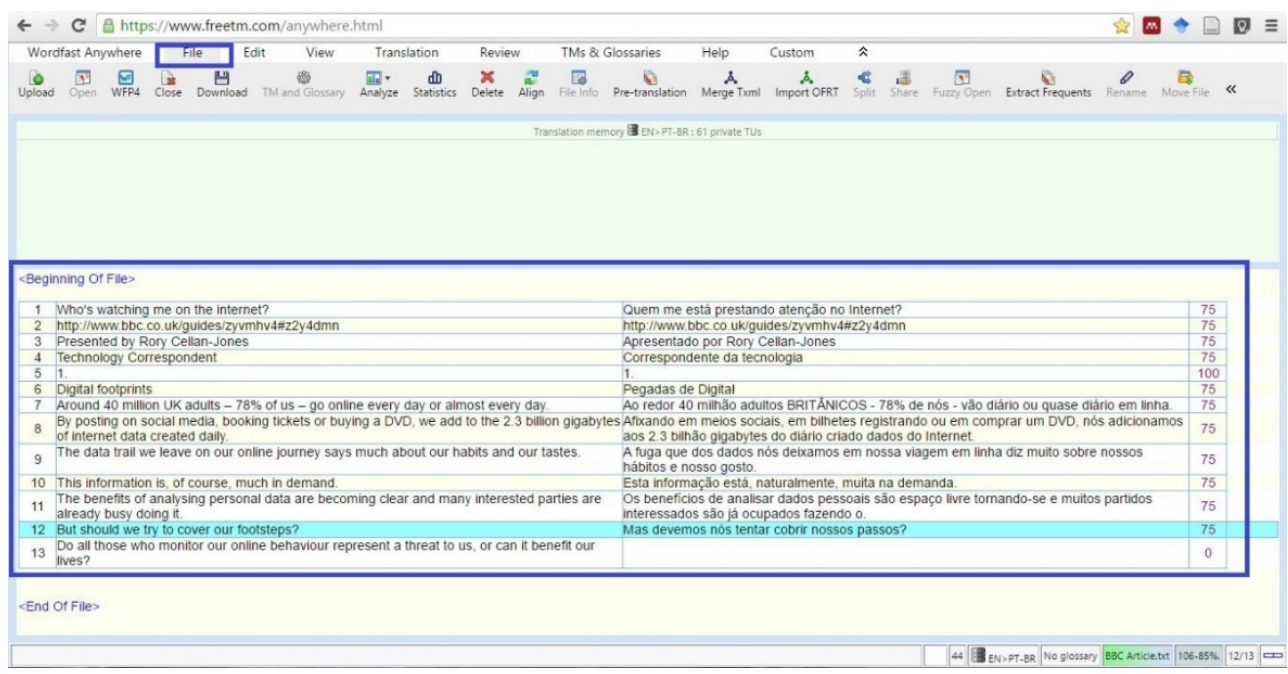

Fonte: Google Translator Toolkit (2016).

Conforme apresentado na Figura 4, podemos visualizar o workbench e a opção "File" do menu em destaque, essa característica viola um dos critérios de usabilidade que diz respeito ao usuário conseguir se localizar no sistema. Para solucionar este problema, o mais indicado é que o programa apresente a opção "Translation" em destaque apenas quando o workbench é apresentado.

4.2. Segunda etapa: avaliação com base em lista de verificação de usabilidade

\subsubsection{Google Translator Toolkit}

Tabela 2 - Resultado da avaliação comparativa da ferramenta Google Translator Toolkit.

\begin{tabular}{|c|c|c|c|}
\hline \multicolumn{2}{|c|}{ Usabilidade } & \multirow{2}{*}{ Descrição } & \multirow{2}{*}{$\begin{array}{c}\text { Pontua- } \\
\text { ção }\end{array}$} \\
\hline Subcaracterística & Atributo & & \\
\hline $\begin{array}{l}\text { Interface do usuá- } \\
\text { rio }\end{array}$ & $\begin{array}{l}\text { Distribuição da } \\
\text { interface do usuá- } \\
\text { rio }\end{array}$ & $\begin{array}{l}\text { Leva um pouco de tempo para } \\
\text { entender a interface. A informação } \\
\text { parcialmente organizada. Às vezes }\end{array}$ & 2 \\
\hline
\end{tabular}


SILVA e FERNANDES, Avaliação comparativa de ferramentas web de apoio à tradução através de critérios de usabilidade e ergonomia cognitiva

\begin{tabular}{|c|c|c|c|}
\hline \multicolumn{2}{|c|}{ Usabilidade } & \multirow{2}{*}{ Descrição } & \multirow{2}{*}{$\begin{array}{l}\text { Pontua- } \\
\text { ção }\end{array}$} \\
\hline Subcaracterística & Atributo & & \\
\hline & & $\begin{array}{l}\text { se faz necessário consultar o ma- } \\
\text { nual. }\end{array}$ & \\
\hline & $\begin{array}{l}\text { Disponibilidade } \\
\text { no idioma reque- } \\
\text { rido }\end{array}$ & $\begin{array}{l}\text { A localização é parcial (a interface } \\
\text { é apresentada no idioma desejado, } \\
\text { mas a documentação não está } \\
\text { traduzida ou vice-versa). }\end{array}$ & 2 \\
\hline & $\begin{array}{l}\text { Compreensão dos } \\
\text { ícones e nomes } \\
\text { das funções }\end{array}$ & $\begin{array}{l}\text { Alguns ícones, nomes de funções } \\
\text { ou menus são difíceis de relacio- } \\
\text { nar à ação que eles realizam. }\end{array}$ & 1 \\
\hline & $\begin{array}{l}\text { Configuração da } \\
\text { aparência }\end{array}$ & $\begin{array}{l}\text { É possível alterar a configuração } \\
\text { da aparência do programa. }\end{array}$ & 1 \\
\hline & & Total: & 6 \\
\hline \multirow[t]{4}{*}{ Facilidade de uso } & $\begin{array}{l}\text { Possibilidade de } \\
\text { navegação e ope- } \\
\text { ração unicamente } \\
\text { através do tecla- } \\
\text { do. }\end{array}$ & $\begin{array}{l}\text { A interação depende quase que } \\
\text { inteiramente da utilização do } \\
\text { mouse. }\end{array}$ & 1 \\
\hline & $\begin{array}{l}\text { Existência de } \\
\text { ajuda contextual. }\end{array}$ & $\begin{array}{l}\text { O programa possui um suporte } \\
\text { básico na interface, mas para } \\
\text { funções avançadas é necessário } \\
\text { recorrer a outras fontes (por } \\
\text { exemplo: manual ou comunidade } \\
\text { de usuários). }\end{array}$ & 2 \\
\hline & $\begin{array}{l}\text { Indicadores de } \\
\text { progresso e men- } \\
\text { sagens de erro }\end{array}$ & $\begin{array}{l}\text { Não existem barras de progresso } \\
\text { nem mensagens informativas. O } \\
\text { usuário muitas vezes não sabe se o } \\
\text { programa está ocupado realizando } \\
\text { algum processo ou se ocorreu } \\
\text { falha. }\end{array}$ & 1 \\
\hline & & Total: & 4 \\
\hline Documentação & Existência & Existe um arquivo de texto do tipo & 2 \\
\hline
\end{tabular}


SILVA e FERNANDES, Avaliação comparativa de ferramentas web de apoio à tradução através de critérios de usabilidade e ergonomia cognitiva

\begin{tabular}{|c|c|c|c|}
\hline \multicolumn{2}{|c|}{ Usabilidade } & \multirow{2}{*}{ Descrição } & \multirow{2}{*}{$\begin{array}{l}\text { Pontua- } \\
\text { ção }\end{array}$} \\
\hline Subcaracterística & Atributo & & \\
\hline & $\begin{array}{l}\text { vários tipos de } \\
\text { documentação }\end{array}$ & $\begin{array}{l}\text { "Leiame.txt", e, pelo menos, outro } \\
\text { guia ou manual de usuário. }\end{array}$ & \\
\hline & $\begin{array}{l}\text { Atualização da } \\
\text { documentação }\end{array}$ & $\begin{array}{l}\text { Toda a documentação está } \\
\text { atualizada com a versão atual do } \\
\text { programa. }\end{array}$ & 3 \\
\hline & $\begin{array}{l}\text { Exaustividade da } \\
\text { documentação }\end{array}$ & $\begin{array}{l}\text { A documentação é muito limitada } \\
\text { ou não há documentação disponí- } \\
\text { vel. }\end{array}$ & 1 \\
\hline & $\begin{array}{l}\text { Existência de } \\
\text { recursos multimí- } \\
\text { dia }\end{array}$ & $\begin{array}{l}\text { A documentação possui algumas } \\
\text { capturas de tela ou outros gráfi- } \\
\text { cos. }\end{array}$ & 2 \\
\hline & & Total: & 8 \\
\hline
\end{tabular}

Fonte: Adaptado de Flórez (2012).

\subsubsection{Wordfast Anywhere}

Tabela 3 - Resultado da avaliação comparativa no sistema Wordfast Anywhere.

\begin{tabular}{|c|c|c|c|}
\hline \multicolumn{2}{|c|}{ Usabilidade } & \multirow{2}{*}{ Descrição } & \multirow{2}{*}{ Pontuação } \\
\hline Subcaracterística & Atributo & & \\
\hline \multirow[t]{3}{*}{$\begin{array}{l}\text { Interface do usuá- } \\
\text { rio }\end{array}$} & $\begin{array}{l}\text { Distribuição da } \\
\text { interface do } \\
\text { usuário }\end{array}$ & $\begin{array}{l}\text { A interface é muito complexa, as } \\
\text { informações não possuem uma } \\
\text { organização clara. } \\
\text { É necessário o uso do manual. }\end{array}$ & 1 \\
\hline & $\begin{array}{l}\text { Disponibilidade } \\
\text { no idioma reque- } \\
\text { rido }\end{array}$ & $\begin{array}{l}\text { O programa e sua documentação de } \\
\text { suporte estão disponíveis apenas } \\
\text { para um idioma diferente do dese- } \\
\text { jado. }\end{array}$ & 1 \\
\hline & $\begin{array}{l}\text { Compreensão } \\
\text { dos ícones e } \\
\text { nomes das fun- } \\
\text { ções }\end{array}$ & $\begin{array}{l}\text { Alguns ícones, nomes de funções } \\
\text { ou menus são difíceis de relacionar } \\
\text { à ação que eles realizam. }\end{array}$ & 1 \\
\hline
\end{tabular}


SILVA e FERNANDES, Avaliação comparativa de ferramentas web de apoio à tradução através de critérios de usabilidade e ergonomia cognitiva

\begin{tabular}{|c|c|c|c|}
\hline \multicolumn{2}{|c|}{ Usabilidade } & \multirow{2}{*}{ Descrição } & \multirow{2}{*}{ Pontuação } \\
\hline Subcaracterística & Atributo & & \\
\hline & $\begin{array}{l}\text { Configuração da } \\
\text { aparência }\end{array}$ & $\begin{array}{l}\text { É possível alterar algumas configu- } \\
\text { rações de aparência (por exemplo: } \\
\text { tipo e tamanho de fonte, cores etc.), } \\
\text { mas essas alterações não podem ser } \\
\text { exportadas para recuperação poste- } \\
\text { rior. }\end{array}$ & 2 \\
\hline & & Total: & 5 \\
\hline \multirow[t]{4}{*}{ Facilidade de uso } & $\begin{array}{l}\text { Possibilidade de } \\
\text { navegação } \mathrm{e} \\
\text { operação unica- } \\
\text { mente através do } \\
\text { teclado. }\end{array}$ & $\begin{array}{l}\text { O programa permite a navegação e } \\
\text { operação com o teclado, mas o } \\
\text { mouse é necessário para algumas } \\
\text { ações. }\end{array}$ & 2 \\
\hline & $\begin{array}{l}\text { Existência de } \\
\text { ajuda contextual. }\end{array}$ & $\begin{array}{l}\text { O programa possui um suporte } \\
\text { básico na interface, mas para fun- } \\
\text { ções avançadas é necessário recor- } \\
\text { rer a outras fontes (por exemplo: } \\
\text { manual ou comunidade de usuá- } \\
\text { rios). }\end{array}$ & 2 \\
\hline & $\begin{array}{l}\text { Indicadores de } \\
\text { progresso e } \\
\text { mensagens de } \\
\text { erro }\end{array}$ & $\begin{array}{l}\text { Existem mensagens } \\
\text { informativas ou barras de progres- } \\
\text { so, mas em a } \\
\text { casos o usuário não sabe se o pro- } \\
\text { grama está ocupado ou se ocorreu } \\
\text { alguma falha. }\end{array}$ & 2 \\
\hline & & Total: & 6 \\
\hline Documentação & $\begin{array}{l}\text { Existência de } \\
\text { vários tipos de } \\
\text { documentação }\end{array}$ & $\begin{array}{l}\text { O programa possui vários tipos } \\
\text { de documentação (Guia rápido ou } \\
\text { manual de instalação, manual do } \\
\text { usuário, manual para desenvolvedo- } \\
\text { res, perguntas frequentes, soluções } \\
\text { de problemas etc.). }\end{array}$ & 3 \\
\hline
\end{tabular}


SILVA e FERNANDES, Avaliação comparativa de ferramentas web de apoio à tradução através de critérios de usabilidade e ergonomia cognitiva

\begin{tabular}{|c|c|c|c|}
\hline \multicolumn{2}{|c|}{ Usabilidade } & \multirow{2}{*}{ Descrição } & \multirow{2}{*}{ Pontuação } \\
\hline Subcaracterística & Atributo & & \\
\hline & $\begin{array}{l}\text { Atualização da } \\
\text { documentação }\end{array}$ & $\begin{array}{l}\text { Toda a documentação está } \\
\text { atualizada com a versão atual do } \\
\text { programa. }\end{array}$ & 3 \\
\hline & $\begin{array}{l}\text { Exaustividade } \\
\text { da documenta- } \\
\text { ção }\end{array}$ & $\begin{array}{l}\text { A documentação abrange de manei- } \\
\text { ra clara todas as funções do pro- } \\
\text { grama. }\end{array}$ & 3 \\
\hline & $\begin{array}{l}\text { Existência de } \\
\text { recursos multi- } \\
\text { mídia }\end{array}$ & $\begin{array}{l}\text { A documentação inclui capturas de } \\
\text { tela, tutoriais ou demonstrações on- } \\
\text { line (como vídeos e passo a passo). }\end{array}$ & 3 \\
\hline & & Total: & 12 \\
\hline
\end{tabular}

Fonte: Adaptado de Flórez (2012).

4.3. Com base em lista de verificação de usabilidade

No último método utilizado, foi percebido que uma investigação comparativa consegue elencar itens não presentes em uma análise mais objetiva. Isso apenas reitera o que foi sugerido por Gow (2003, p. 68), de que é desejável a utilização de avaliação humana no processo, pois a mesma serve para validar a utilidade de qualquer métrica aplicada. Outro fator interessante da avaliação comparativa é elencado por Höge et al. (1993, apud EAGLES, 1996, p. 149) quando destacam que este tipo de análise pode ser a "única forma de obter resultados úteis de atributos cujos valores são definidos apenas em uma escala de comparação". Os autores também advertem que os resultados devem tentar garantir que a atenção dada aos sistemas seja a mesma.

Com relação à Hipótese 1 (vide item 3), vimos que as duas ferramentas diferem muito entre si e têm maior enfoque nas funcionalidades do que na interação do usuário com o sistema, o que vem a confirmar tal hipótese. Acredita-se que a avaliação tenha sido conduzida da forma mais imparcial possível, visto que procurou analisar pontos semelhantes nos dois sistemas, bem como seguiu a orientação das hipóteses formuladas. Verifi- 
SILVA e FERNANDES, Avaliação comparativa de ferramentas web de apoio à tradução através de critérios de usabilidade e ergonomia cognitiva

cou-se que entre as ferramentas analisadas, nenhuma consegue atender de forma satisfatória aos itens da avaliação realizada através da lista de verificação, conforme é apresentado sobre o Google Translator Toolkit na Tabela 4 e da Wordfast Anywhere na Tabela 5. Tal aspecto vem a confirmar a Hipótese 2 de que métodos de usabilidade não são aplicados antes da utilização dos sistemas por seus usuários.

Tabela 4 - Resultado da avaliação comparativa na ferramenta Google Translator Toolkit (2016).

\begin{tabular}{|l|c|c|c|}
\hline \multicolumn{4}{|c|}{ Usabilidade } \\
\hline Subcaracterística & Pontuação & \multicolumn{2}{|c|}{ Critério de aceitação } \\
\hline Interface de usuário & 6 & Não atendido & X \\
\hline Facilidade de uso & 4 & Não atendido & X \\
\hline Documentação & 8 & Atendido & $\checkmark$ \\
\hline Fonte: Própria autora.
\end{tabular}

$\mathrm{Na}$ Tabela 4, percebe-se que dois itens analisados, "interface do usuário" e "facilidade de uso", não são atendidos pelo critério de aceitação, indicando que sejam feitas melhorias de forma a prover melhor satisfação de seus usuários. Vemos que, apenas com a aplicação de uma pequena lista de verificação já é possível identificar falhas relacionadas à usabilidade e ergonomia cognitiva.

Tabela 5 - Resultado da avaliação comparativa na ferramenta Wordfast Anywhere (2016).

\begin{tabular}{|l|c|c|c|}
\hline \multicolumn{3}{|c|}{ Usabilidade } \\
\hline Subcaracterística & Pontuação & \multicolumn{2}{c|}{ Critério de aceitação } \\
\hline Interface de usuário & 5 & Não atendido & X \\
\hline Facilidade de uso & 6 & Atendido & $\checkmark$ \\
\hline Documentação & 12 & Atendido & $\checkmark$ \\
\hline
\end{tabular}

Fonte: Própria autora.

Na Tabela 5, verifica-se que o item "interface do usuário" não atende aos requisitos determinados pela lista de verificação. Isso demonstra que o programa analisado requer ajustes neste critério. Pode-se inferir que a preocupação das ferramentas esteja mais relacionada ao produto final, ou seja, à tradução em si, do que com a experiência do usuário - uso do pro- 
SILVA e FERNANDES, Avaliação comparativa de ferramentas web de apoio à tradução através de critérios de usabilidade e ergonomia cognitiva

grama pelo tradutor. Tal conclusão demonstra que é necessária investigação mais aprofundada na área, no que diz respeito à utilização de métodos que auxiliem no desenvolvimento de novos sistemas.

\section{Conclusões e encaminhamentos}

Ao longo do artigo, os principais tópicos, tecnologias de tradução e tradução assistida por computador, foram apresentados a partir do referencial teórico com a abordagem da ergonomia cognitiva e usabilidade. Da mesma forma, os procedimentos utilizados na avaliação comparativa foram dispostos para introduzir os métodos propostos. Os resultados iniciais mostraram indícios de que o emprego de alguns métodos que consideram princípios de usabilidade e ergonomia cognitiva podem ter baixo custo e ser de fácil acesso, necessitando-se apenas uma disseminação maior sobre como aplicá-los às ferramentas de tradução.

Acredita-se que o estudo apresentado consiga indicar a necessidade de pesquisas complementares com ênfase na usabilidade e ergonomia cognitiva, bem como estudos adicionais que possam complementar o proposto neste artigo, que é o de diminuir problemas acerca da usabilidade e ergonomia em ferramentas relacionadas à tradução. Acredita-se que proporcionando tal conhecimento aos usuários da área, bem como aos estudantes, pesquisadores e professores, complemente-se a capacidade técnica desses profissionais em relação às reflexões sobre suas próprias necessidades. Isso levaria a uma melhor definição de requisitos e especificação de programa, e consequentemente a um desenvolvimento de ferramentas mais próximas do contexto em que se inserem os usuários da área de tradução.

\section{Referências}

ALCINA, A. Translation technologies. Scope, tools and resources. Target, v. 20, n. 1, 2008, pp. 79-102.

BOWKER, L. Computer-aided Translation - Translator training. In: CHAN, S. Routledge encyclopedia of translation technology. New York: Routledge, 2015, p. 88-104.

BOWKER, L; FISHER, D. Computer-aided translation. In: GAMBIER, Y.; DOORSLAER, L. Handbook of translation studies. Amsterdam: John Benjamins B.V., 2010, p. 60-65. 
SILVA e FERNANDES, Avaliação comparativa de ferramentas web de apoio à tradução através de critérios de usabilidade e ergonomia cognitiva

CARROLL, J. M. Human Computer Interaction (HCI). In: SOEGAARD, Mads; DAM, Rikke Friis (ed.). Encyclopedia of Human-Computer Interaction. Aarhus, Dinamarca: The Interaction-Design.org Foundation. 2009. Disponível em: <https://www.interaction-design.org/literature/book/theencyclopedia-of-human-computer-interaction-2nd-ed/human-computerinteraction-brief-intro>. Acesso em: 03 jan. 2016.

CHAN, S. Routledge encyclopedia of translation technology. New York: Routledge, 2015.

COCKTON, G. Usability Evaluation. In: The Encyclopedia of HumanComputer Interaction, 2nd Ed. 2013. Disponível em: $<$ https://www.interaction-design.org/literature/book/the-encyclopedia-ofhuman-computer-interaction-2nd-ed/usability-evaluation>. Acesso em: 30 mar. 2016.

CYBIS, W. et al. Ergonomia e usabilidade: conhecimentos, métodos e aplicações. São Paulo: Novatec Editora, 2010.

EAGLES MT Evaluation Working Group. EAGLES (Evaluation of Natural Language Processing Systems). Final Report. EAGLES Document EAGEWG- PR.2, ISBN 87-90708- 00-8. Center for Sprogteknologi, Copenhagen, 1996.

ERGOLIST (2011). Disponível em: <http://www.labiutil.inf.ufsc.br/ergolist/>. Acesso em: 10 set. 2014.

FLÓREZ, S. Tecnologías libres para la traducción y su evaluación. 2012. $281 \mathrm{f}$. Universitat Jaume I, Castellón de la Plana, Espanha, 2012.

GAMBIER, Y; DOORSLAER, L. Handbook of translation studies. Amsterdam: John Benjamins B.V., 2010.

GARCIA, I. Computer-aided Translation Systems. Routledge Encyclopedia of Translation Technology, p. 68-87, 2015.

GOOGLE TRANSLATOR TOOLKIT. Google Inc., 2016. Disponível em: $<$ https://translate.google.com/toolkit/>. Acesso em: 20 mai. 2016.

GOW, F. Metrics for Evaluating Translation Memory Software. 2003. 189f. Tese (Doutorado em Língua Inglesa e Linguística Aplicada - Tradução) Curso de Pós-Graduação em Estudos Literários e Inglês, University of Ottawa, Ontario, Canadá, 2003.

HEWETT, T. T et al. ACM SIGCHI curricula for human-computer interaction. ACM, 1992.

INTERNATIONAL ERGONOMICS ASSOCIATION. What is ergonomics? Definition and Domains of Ergonomics. IEA, 2000. Disponível em: <http://www.iea.cc/whats/index.html>. Acesso em: 15 mar. 2016.

INTERNATIONAL ORGANIZATION FOR STANDARDIZATION. ISO 9241-11: Ergonomic requirements for office work with visual display terminals (VDTs). pt.11: Guidance on usability. Geneva: ISO, 2002. IV, 22p. 
SILVA e FERNANDES, Avaliação comparativa de ferramentas web de apoio à tradução através de critérios de usabilidade e ergonomia cognitiva

KENNY, D. Electronic tools and resources for translators. In: MALKMKJAER, K.; WINDLE, K. The Oxford handbook of translation studies. Oxford: Oxford University Press, 2011.

LAW, E. L. C. et al. Towards the maturation of IT usability evaluation (MAUSE). In: Human-Computer Interaction-INTERACT 2005. Springer Berlin Heidelberg. 2005, p. 1134-1137.

MALMKJÆR, K.; WINDLE, K. The Oxford Handbook of Translation Studies. 2011.

MASSEY G.; EHRENSBERGER-DOW, M. Technical and Instrumental Competence in the Translator's Workplace: Using Process Research to Identify Educational and Ergonomic Needs, ILCEA, no. 14, 2011.

NIELSEN, J. Usability Engineering. San Francisco: Morgan Kaufmann Publishers, 1993.

Nielsen Norman Group. 2002. Disponível em: $<$ https://www.nngroup.com/topic/heuristic-evaluation/>. Acesso em: 03 mar. 2015.

NIELSEN, J.; MOLICH, R. Heuristic evaluation of user interfaces. In: Proceedings of the SIGCHI conference on Human factors in computing systems, 1990, p. 249256. Disponível em: <http://portal.acm.org/citation.cfm?doid=97243.97281>. Acesso em: 9 abr. 2016.

QUAH, C. K. Translation and Technology. Nova Iorque: Palgrave Macmillan, $2006 . \quad$ Disponível em: <http://www.palgraveconnect.com/doifinder/10.1057/9780230287105>.

Acesso em: 12 maio 2016.

RUBIN, J.; CHISNELL, D. Handbook of Usability Testing: How to Plan, Design, and Conduct Effective Tests. Indiana: John Wiley \& Sons, $2^{\mathrm{a}}$ edição, 2008. Disponível

em:

$<$ http://scholar.google.com/scholar?hl=en\&btnG=Search\&q=intitle:Handbook + of + usabi-

lity+testing\#3 \nhttp://scholar.google.com/scholar?hl=en\&btnG=Search\&q=intitle:

Handbook+of+Usability+Testing, $+1994 \# 1>$.

SCHADE, A. Competitive Usability Evaluations: Learning from Your Competition. Disponível em: $<$ https://www.nngroup.com/articles/competitive-usability-evaluations/>. Acesso em: 20 maio 2016.

WORDFAST ANYWHERE, versão 4.10.7. Wordfast, 2016. Disponível em: $<$ https://www.freetm.com/anywhere.html $>$. Acesso em: 01 ago. 2016.

Resumo: O objetivo deste trabalho é apresentar uma análise comparativa, centrada no usuário, que foi realizada em duas ferramentas de apoio à tradução disponíveis on-line: Google Translator Toolkit e Wordfast Anywhere. Como principal método de investigação, temos a avaliação exploratória 
SILVA e FERNANDES, Avaliação comparativa de ferramentas web de apoio à tradução através de critérios de usabilidade e ergonomia cognitiva

e aplicação de lista de verificação de usabilidade e ergonomia cognitiva. Os resultados iniciais mostram que o emprego de métodos de avaliação deste tipo pode ter baixo custo e ser de fácil acesso, necessitando-se apenas de uma disseminação maior sobre como aplicá-los às ferramentas de tradução. Palavras-chave: Estudos da tradução. Ferramentas de apoio à tradução. Usabilidade e ergonomia cognitiva.

\begin{abstract}
The aim of this paper is to present a user-centered comparative analysis of two CAT tools available on-line: Google Translator Toolkit and Wordfast Anywhere. As the central research method, we have applied an exploratory evaluation and a usability and cognitive ergonomics checklist. Initial results show that the use of some of these methods may be low-cost and easily accessible, requiring only further dissemination about how applying them to translation tools.
\end{abstract}

Keywords: Translation Studies. CAT tools. Usability and cognitive ergonomics. 
SILVA e FERNANDES, Avaliação comparativa de ferramentas web de apoio à tradução através de critérios de usabilidade e ergonomia cognitiva

\section{Apêndice A - Lista de verificação para a avaliação comparativa}

Figura 5 - Atributos necessários para avaliação - interface do usuário.

\begin{tabular}{|c|c|c|c|c|}
\hline \multicolumn{2}{|c|}{ Usabilidade } & \multicolumn{3}{|c|}{ Pontuação } \\
\hline $\begin{array}{c}\text { Sub } \\
\text { Característica }\end{array}$ & Atributo & 1 & 2 & 3 \\
\hline \multirow[t]{4}{*}{$\begin{array}{l}\text { Interface do } \\
\text { usuário }\end{array}$} & $\begin{array}{l}\text { Distribuição da } \\
\text { interface do } \\
\text { usuário }\end{array}$ & $\begin{array}{l}\text { A interface é muito } \\
\text { complexa, as } \\
\text { informações não } \\
\text { possuem uma } \\
\text { organização clara. } \\
\text { É necessário o uso do } \\
\text { manual. }\end{array}$ & $\begin{array}{l}\text { Leva um pouco de tempo } \\
\text { para entender a interface. } \\
\text { A informação } \\
\text { parcialmente organizada. } \\
\text { As vezes se faz necessário } \\
\text { consultar o manual. }\end{array}$ & $\begin{array}{l}\text { A interface é simples e intuitiva, a } \\
\text { informação é bem organizada. } \\
\text { Praticamente não é necessário o } \\
\text { uso de manual. }\end{array}$ \\
\hline & $\begin{array}{l}\text { Disponibilidade } \\
\text { no idioma } \\
\text { requerido }\end{array}$ & $\begin{array}{l}\text { O programa e sua } \\
\text { documentação de } \\
\text { suporte estão } \\
\text { disponíveis apenas } \\
\text { para um idioma } \\
\text { diferente do desejado. }\end{array}$ & $\begin{array}{l}\text { A localização é parcial (a } \\
\text { interface é apresentada no } \\
\text { idioma desejado, mas a } \\
\text { documentação não está } \\
\text { traduzida ou vice-versa). }\end{array}$ & $\begin{array}{l}\text { O programa é totalmente } \\
\text { localizado para o idioma } \\
\text { desejado, tanto a interface do } \\
\text { usuário como as ajudas e outras } \\
\text { documentações. }\end{array}$ \\
\hline & $\begin{array}{l}\text { Compreensão } \\
\text { dos ícones e } \\
\text { nomes das } \\
\text { funções }\end{array}$ & $\begin{array}{l}\text { Alguns ícones, nomes } \\
\text { de funções ou menus } \\
\text { são dificeis de } \\
\text { relacionar com a ação } \\
\text { eles realizam. }\end{array}$ & $\begin{array}{l}\text { É fácil relacionar os } \\
\text { ícones, nomes de funções } \\
\text { e menus com as ações que } \\
\text { eles realizam. }\end{array}$ & $\begin{array}{l}\text { É fácil de relacionar os nomes das } \\
\text { funções e menus com as ações } \\
\text { que esses realizam. Há também } \\
\text { textos alternativos (tooltips }{ }^{8} \text { ) para } \\
\text { explicar as funções dos ícones. }\end{array}$ \\
\hline & $\begin{array}{l}\text { Configuração } \\
\text { da aparência }\end{array}$ & $\begin{array}{l}\text { É possível alterar a } \\
\text { configuração da } \\
\text { aparência do } \\
\text { programa. }\end{array}$ & $\begin{array}{l}\text { É possível alterar algumas } \\
\text { configurações de } \\
\text { aparência (por exemplo: } \\
\text { tipo e tamanho de fonte, } \\
\text { cores etc.), mas essas } \\
\text { alterações não podem ser } \\
\text { exportadas para } \\
\text { recuperação posterior. }\end{array}$ & $\begin{array}{l}\text { É possível fazer algumas } \\
\text { mudanças nas configurações de } \\
\text { apresentação (por exemplo: tipo e } \\
\text { tamanho de fonte, cores etc.) e } \\
\text { essas mudanças podem ser } \\
\text { exportadas. }\end{array}$ \\
\hline
\end{tabular}

${ }^{8}$ Uma mensagem que aparece quando o cursor do mouse está posicionado sobre determinado ícone, imagem, hyperlink, ou outro elemento em uma interface gráfica.

Fonte: Adaptado de Flórez (2012, p. 155-156). 
SILVA e FERNANDES, Avaliação comparativa de ferramentas web de apoio à tradução através de critérios de usabilidade e ergonomia cognitiva

Figura 6 - Atributos necessários para avaliação - facilidade de uso.

\begin{tabular}{|c|c|c|c|c|}
\hline \multicolumn{2}{|c|}{ Usabilidade } & \multicolumn{3}{|c|}{ Pontuação } \\
\hline $\begin{array}{c}\text { Sub } \\
\text { Característica }\end{array}$ & Atributo & 1 & 2 & 3 \\
\hline \multirow[t]{3}{*}{$\begin{array}{l}\text { Facilidade de } \\
\text { uso }\end{array}$} & $\begin{array}{l}\text { Possibilidade } \\
\text { de navegação e } \\
\text { operação } \\
\text { unicamente } \\
\text { através do } \\
\text { teclado. }\end{array}$ & $\begin{array}{l}\text { A interação depende } \\
\text { quase que } \\
\text { inteiramente da } \\
\text { utilização do mouse. }\end{array}$ & $\begin{array}{l}\text { O programa permite a } \\
\text { navegação e operação com } \\
\text { o teclado, mas o mouse é } \\
\text { necessário para algumas } \\
\text { ações. }\end{array}$ & $\begin{array}{l}\text { A interface é projetada para } \\
\text { permitir navegação e operação } \\
\text { apenas com o uso do teclado, sem } \\
\text { depender do mouse. }\end{array}$ \\
\hline & $\begin{array}{l}\text { Existência de } \\
\text { ajuda } \\
\text { contextual. }\end{array}$ & $\begin{array}{l}\text { O programa não } \\
\text { possui ajuda acessível } \\
\text { dentro da interface; é } \\
\text { necessário abrir o } \\
\text { manual do usuário em } \\
\text { outro aplicativo ou } \\
\text { usar outras fontes (por } \\
\text { exemplo: páginas de } \\
\text { busca ou wiki). }\end{array}$ & $\begin{array}{l}\text { O programa possui um } \\
\text { suporte básico na } \\
\text { interface, mas para } \\
\text { funções avançadas é } \\
\text { necessário recorrer a } \\
\text { outras fontes (por } \\
\text { exemplo: manual ou } \\
\text { comunidade de usuários). }\end{array}$ & $\begin{array}{l}\text { O programa possui ajuda na } \\
\text { maioria das funções que podem } \\
\text { ser acessadas sem sair da } \\
\text { aplicação. }\end{array}$ \\
\hline & $\begin{array}{l}\text { Indicadores de } \\
\text { progresso e } \\
\text { mensagens de } \\
\text { erro }\end{array}$ & $\begin{array}{l}\text { Não existem barras de } \\
\text { progresso nem } \\
\text { mensagens } \\
\text { informativas. O } \\
\text { usuário muitas vezes } \\
\text { não sabe se o } \\
\text { programa está } \\
\text { ocupado realizando } \\
\text { algum processo ou se } \\
\text { ocorreu falha. }\end{array}$ & $\begin{array}{l}\text { Existem mensagens } \\
\text { informativas ou barras de } \\
\text { progresso, mas em alguns } \\
\text { casos o usuário não sabe } \\
\text { se o programa está } \\
\text { ocupado ou se ocorreu } \\
\text { alguma falha. }\end{array}$ & $\begin{array}{l}\text { Existem barras de progresso, } \\
\text { mensagens de erro ou outras } \\
\text { mensagens informativas que são } \\
\text { apresentadas ao usuário para que } \\
\text { o mesmo esteja ciente sobre a } \\
\text { atividade do programa ou } \\
\text { possiveis falhas. }\end{array}$ \\
\hline
\end{tabular}

Fonte: Adaptado de Flórez (2012, p. 155-156).

Figura 7 - Atributos necessários para avaliação - documentação.

\begin{tabular}{|c|c|c|c|c|}
\hline \multicolumn{2}{|c|}{ Usabilidade } & \multicolumn{3}{|c|}{ Pontuação } \\
\hline $\begin{array}{c}\text { Sub } \\
\text { Característica }\end{array}$ & Atributo & 1 & 2 & 3 \\
\hline \multirow[t]{4}{*}{ Documentação } & $\begin{array}{l}\text { Existência de } \\
\text { vários tipos de } \\
\text { documentação }\end{array}$ & $\begin{array}{l}\text { Está disponível } \\
\text { apenas um arquivo de } \\
\text { texto do tipo } \\
\text { "Leiame.txt" e não há } \\
\text { documentação } \\
\text { disponível. }\end{array}$ & $\begin{array}{l}\text { Existe um arquivo de texto } \\
\text { do tipo "Leiame.txt", e } \\
\text { pelo menos outro guia ou } \\
\text { manual de usuário. }\end{array}$ & $\begin{array}{l}\text { O programa possui vários tipos } \\
\text { de documentação (Guia rápido ou } \\
\text { manual de instalação, manual do } \\
\text { usuário, manual para } \\
\text { desenvolvedores, perguntas } \\
\text { frequentes, soluções de problemas } \\
\text { etc.). }\end{array}$ \\
\hline & $\begin{array}{l}\text { Atualização da } \\
\text { documentação }\end{array}$ & $\begin{array}{l}\text { Toda a documentação } \\
\text { se refere a versões } \\
\text { anteriores do } \\
\text { programa ou não há } \\
\text { documentação. }\end{array}$ & $\begin{array}{l}\text { Algumas partes da } \\
\text { documentação não } \\
\text { correspondem à versão } \\
\text { atual do } \\
\text { programa. }\end{array}$ & $\begin{array}{l}\text { Toda a documentação está } \\
\text { atualizada com a versão atual do } \\
\text { programa. }\end{array}$ \\
\hline & $\begin{array}{l}\text { Exaustividade } \\
\text { da } \\
\text { documentação }\end{array}$ & $\begin{array}{l}\text { A documentação é } \\
\text { muito limitada ou não } \\
\text { há documentação } \\
\text { disponivel. }\end{array}$ & $\begin{array}{l}\text { A documentação não } \\
\text { inclui informações sobre } \\
\text { algumas funçôes } \\
\text { importantes. }\end{array}$ & $\begin{array}{l}\text { A documentação abrange de } \\
\text { maneira clara todas as funções do } \\
\text { programa. }\end{array}$ \\
\hline & $\begin{array}{l}\text { Existência de } \\
\text { recursos } \\
\text { multimídia }\end{array}$ & $\begin{array}{l}\text { Não existe auxílio } \\
\text { visual nem recursos } \\
\text { multimídia como } \\
\text { parte da } \\
\text { documentação, ou não } \\
\text { há } \\
\text { documentação. }\end{array}$ & $\begin{array}{l}\text { A documentação possui } \\
\text { algumas capturas de tela } \\
\text { ou outros gráficos. }\end{array}$ & $\begin{array}{l}\text { A documentação inclui capturas } \\
\text { de tela, tutoriais ou } \\
\text { demonstrações online (como } \\
\text { vídeos e passo a passo). }\end{array}$ \\
\hline
\end{tabular}

Fonte: Adaptado de Flórez (2012, p. 155-156). 